\title{
Histological Evaluation of Experimentally Induced Critical Size Defect Skin Wounds Using Exosomal Solution of Mesenchymal Stem Cells Derived Microvesicles
}

\author{
Omar S. El-Tookhy ${ }^{1}$, Ashraf A. Shamaa ${ }^{1}$, Gehan G. Shehab ${ }^{2}$, Ahmed N. Abdallah², Omnia M. Azzam ${ }^{3}$ \\ ${ }^{I}$ Department of Surgery, Anesthesiology and Radiology, Faculty of Veterinary Medicine, Cairo University, Cairo \\ ${ }^{2}$ Department of Pathology, Animal Health Research Institute, Ministry of Agriculture, Cairo \\ ${ }^{3}$ Department of Surgery, The Military Veterinary Hospital, Cairo, Egypt
}

Background and Objectives: The present study investigated whether MSCs derived microvesicles (MVs) or (Exosomes) can exert therapeutic effects on an experimental model of cutaneous injury and explored the underlying involving mechanisms.

Methods and Results: Three bilateral full thickness circular wounds were created on the back of two groups of dogs using 2 -cm dermal punch. The wounds were at least $2.5 \mathrm{~cm}$ apart. Saline was subcutaneously injected in 4 places around each wound area in group-I (control), whereas an equal volume of exosomal solution of MSCs derived MVs was similarly injected in group-II. The findings demonstrated that MSCs derived MVs had significantly promoted cutaneous wound healing, collagen synthesis, and vascularization at wound sites. The application of the exosomal solution had not only promoted the generation of newly formed vessels, but also have accelerated their development and maturation leading to a faster healing process.

Conclusions: MSC-Exosomes appeared to be a superior candidate for treating cutaneous wounds than their originator cells, and may represent a promising opportunity to develop a novel cell-free therapy approach that might overcome the obstacles and risks associated with the use of native or engineered stem cells transplantation therapy.

Keywords: Histological, Critical size defect, Mesenchymal stem cells, Microvesicles, Healing

\section{Introduction}

The repair of wounds is one of the most complex bio-

Accepted for publication September 2, 2017, Published online November 30, 2017

Correspondence to Omnia M. Azzam

Department of Surgery, The Military Veterinary Hospital, El-Nasr Road, Nasr City, Cairo, Egypt

Tel: +201003452866, Fax: +20 (2) 357-2540

E-mail: omnia.azzam.90@gmail.com

(c) This is an open-access article distributed under the terms of the Creative Commons Attribution Non-Commercial License (http://creativecommons.org/ licenses/by-nc/4.0/), which permits unrestricted non-commercial use, distribution, and reproduction in any medium, provided the original work is properly cited.

Copyright (c) 2017 by the Korean Society for Stem Cells Research logical processes that occur during human life (1). It requires a coordinated interplay among cells, growth factors, and extracellular matrix proteins (2). Microvesicles (MVs) or Exosomes are membrane vesicles that are released by many types of cells from the endosomal compartment, or as shedding vesicles from the cell surface (3). These exosomes are considered important mediators of cell-to-cell communication $(3,4)$. As vehicles of information, these exosomes may act as paracrine or endocrine mediators that interact with neighboring cells, modulate immune responses, promote self-repair from cells that survive injury and play important role in communication between stem and injured tissue cells $(3,4)$.

Other than being mediators of cell-to-cell communication, MSC-derived exosomes have functions similar to 
those of MSCs, such as repairing tissue damage and suppressing inflammatory responses (4). Compared with the cells from where they originate, exosomes produced by MSCs are expected to have several advantages in the wound environment. For example, exosomes are more stable due to their lipid bilayer shell which could avert proteolytic degradation and hence can effectively transfer signals to target cells (e.g., fibroblasts and endothelial cells). Additionally, exosomes contain many potential regulatory components including miRNAs, mRNAs, and proteins, which can be transferred as a type of "physiological lipofection" to recipient cells to modify their characteristics (5).

Moreover, exosomes are more re-servable, have no risk of aneuploidy, a lower possibility of immune rejection following in vivo allogeneic administration, and therefore may provide an alternative therapy for various diseases $(4,5)$.

In the present study, we histologically studied the therapeutic effects of MSC derived exosomes in cutaneous wound healing. Healing was assessed using histological parameters such as: re-epithelialization, cellularity, angiogenesis, and dermal structural regeneration. Confirmatory immuno-histochemistry tests were conducted.

\section{Materials and Methods}

\section{Experimental animals}

Six apparently healthy dogs weighing (20 25 kg), age (2 3 years) were used in this study. The study was approved by Institutional Animal Care and Use Committee. Dogs were housed at separate kennels, fed on standard dog's food with free access to drinking water.

\section{Animal grouping}

Dogs were randomly and equally allocated into 2 groups.

Group-I (control): treated with saline.

Group-Il (treated): treated with MSCs-derived exosomes.

Three full-thickness skin wounds were induced bilaterally on the back of each dog. Wounds were evaluated daily for appearance and size. Histological samples were taken at the $3 \mathrm{rd}, 7$ th and the 14 th day post treatment. At the end of the experiment, all dogs received medical treatment to the remaining of their skin wounds (Mepore sterile dermal patches, Molnlycke ${ }^{\circledR}$ health care) and Bivatracin topical antibiotic spray (Neomycin and bacitracin, ACDIMA ${ }^{\circledR}$ International) until complete healing.

\section{Induction of skin wound}

Experimental dogs were anesthetized using general anesthetic regimen after overnight fasting. Three bilateral circular wounds of $2 \mathrm{~cm}$ in diameter were created on the back of each dog by using a dermal punch. The wounds were at least $2.5 \mathrm{~cm}$ apart. The day on which the wounds were created was designed as day 0 .

\section{Isolation and expansion of canine MSCs-derived MVs}

One month before commence of the experiment, fresh Bone Marrow (BM) was aspirated from the iliac crest of healthy dogs and MSCs were isolated, propagated, and identified. Microvesicles where then isolated for usage.

Bone marrow MSCs isolation: Proper sterile technique was used and all solutions and equipment coming into contact with cells were sterile.

Bone marrow MSCs propagation: Bone marrow samples were over-layered on $20 \mathrm{ml} \mathrm{Ficoll,} \mathrm{and} \mathrm{then} \mathrm{centri-}$ fuged for $15 \mathrm{~min}$. at $400 \times \mathrm{g}$. Bone marrow mononuclear cell fractions (BM-MNCs) were isolated. The layer of BM-MNC layer was carefully aspirated and resuspended in PBS and centrifuged for 10 minutes at $200 \times \mathrm{g}$. Then the cell pellet was resuspended in PBS for washing and centrifuged for 10 minutes at $200 \times \mathrm{g}$. And the pellet was re-suspended in a final volume of $2 \mathrm{ml}$ of RBCs lysis buffer and incubated for 10 minutes at $4^{\circ} \mathrm{C}$. PBs was added for a final volume of $10 \mathrm{ml}$ and centrifuged again to remove the lysis buffer. Cell pellet was suspended in complete culture medium containing Dulbecco's modified Eagle's medium (DMEM) supplemented with 10\% fetal bovine serum and antibiotics $(100 \mathrm{U} / \mathrm{ml}$ penicillin and 100 $\mu \mathrm{g} / \mathrm{ml}$ streptomycin). Cells were incubated at $37^{\circ} \mathrm{C}$ in $5 \%$ $\mathrm{CO}_{2}$ for 24 hours. Media was removed to remove non-specific cells leaving only adherent cells. Fresh complete medium was added and incubated at $37^{\circ} \mathrm{C}$ in $5 \% \mathrm{CO}_{2}$ and media was changed every $2 \sim 3$ days. When cells reached $70 \sim 80 \%$ confluence, cultures were washed twice with PBS and cells were trypsinized with $0.25 \%$ Trypsin-EDTA (GIBCO) for 3 minutes at $37^{\circ} \mathrm{C}$, complete medium was added to stop the action of trypsin. Centrifuged for $10 \mathrm{mi}-$ nutes at $200 \times \mathrm{g}$. Cell pellets were resuspended in complete medium. The resulting cultures were referred to as first-passage cultures. The last 3 fore mentioned steps were repeated until the fourth passage was attained.

Identification of BM-derived MSCs: Cells were identified as MSCs by their morphology and adherence on tissue culture flask. Then Flow cytometric analysis of the cultured MSCs surface markers was done using CD105, CD90 and CD73.

Isolation and FACS Analysis of MVs: MVs obtained from the supernatants of the third passage of MSCs $\left(5 \times 10^{6}\right.$ cells $\left./ \mathrm{ml}\right)$ were cultured in RPMI deprived of FBS and supplemented with $0.5 \%$ of bovine serum albumin (BSA, Sigma). After centrifugation at $2000 \mathrm{~g}$ for $20 \mathrm{~min}$ 
to remove debris, cell-free supernatants were centrifuged at 100,000 g (Beckman Coulter Optima L 90K ultracentrifuge) for $1 \mathrm{~h}$ at $4^{\circ} \mathrm{C}$, washed in serum-free medium 199 containing HEPES $25 \mathrm{mM}$ (Sigma) and submitted to a second ultracentrifugation under the same conditions. The protein content was quantified by the Bradford method (BioRad, Hercules, CA). Electron microscopy analyses of MVs were performed. Purified MVs cultured overnight in the medium used for collection of MVs. Images were obtained by secondary electron at a working distance of 15 to $25 \mathrm{~mm}$ and an accelerating voltage of 20 and $30 \mathrm{kV}$. Digital acquisition and analysis were performed using the Jeol T300 system. Cytofluorimetric analysis was performed using the following FITC- or PE-conjugated antibodies: CD63, CD44 (MiltenyiBiotec) and CD73 (Becton Dickinson). FITC or PE mouse nonimmune isotypic IgG (DakoCytomation) was used as a control.

\section{Treatment}

Twenty-four hours after wound creation, equal amounts ( $1 \mathrm{ml}$ ) of saline and exosomal solution were subcutaneously injected in 4 cardinal places around each wound. The amount of exosomes injected equals the amount produced by $2 \times 10^{6} \mathrm{MSCs} / 1 \mathrm{ml} /$ wound.

Monitoring of the general condition and wound healing of the experimental dogs was performed daily, and the wounds were photographed.

\section{Evaluation}

Physical evaluation of the wounds: Wound-size reduction was calculated using the equation: wound-size reduction $=\left(A_{i}-A_{f}\right) / A_{i} \times 100$, (where $A_{i}$ is the initial wound area, and $A_{f}$ is the wound area at Day 3, 7 or 14 post-wounding) (6).

Histological analyses: On days 3, 7 and 14, each ex- perimental dog was sedated and tissue samples were harvested with $0.5 \mathrm{~cm}$ of the peripheral unwounded skin using $2.5 \mathrm{~cm}$ dermal biopsy. Samples were pinned on a plastic plate (to keep the tissue flat) and fixed in $10 \%$ buffered Formalin, dehydrated with a graded Alcohol series, embedded in Paraffin, and sectioned into $4-\mu \mathrm{m}$-thick sections (6).

Hematoxylin and Eosin (H\&E) staining was used for histological observations: For comparison of the rate of re-epithelialization in different groups, and the epithelial gap was evaluated. Masson's trichrome staining was used to determine the degree of collagen synthesis.

Immunohistochemistry: CD31 and alpha smooth muscle actin ( $\alpha$-SMA) markers were detected by immunoperoxidase technique and evaluated by light microscope to study exosome-induced angiogenesis during the wound healing process. For immunoperoxidase staining, excised skin from the wound sites was fixed in $10 \%$ formalin, dehydrated with different grades of alcohol series, embedded in paraffin, and sectioned into $4-\mu \mathrm{m}$-thick sections on positive slides.

\section{Results}

\section{Physical evaluation of the wounds}

Wound reduction size: Induced wounds treated with exosomal solution showed quicker healing than their counterparts treated with saline (Fig. 1). All results were significant during the three observation periods, $(p=0.001)$ at 3 and 7 days and $(p=0.003)$ at the $14^{\text {th }}$ day. The reduction percentages for the two experimental groups are shown in (Table 1) and drawn (Fig. 2).
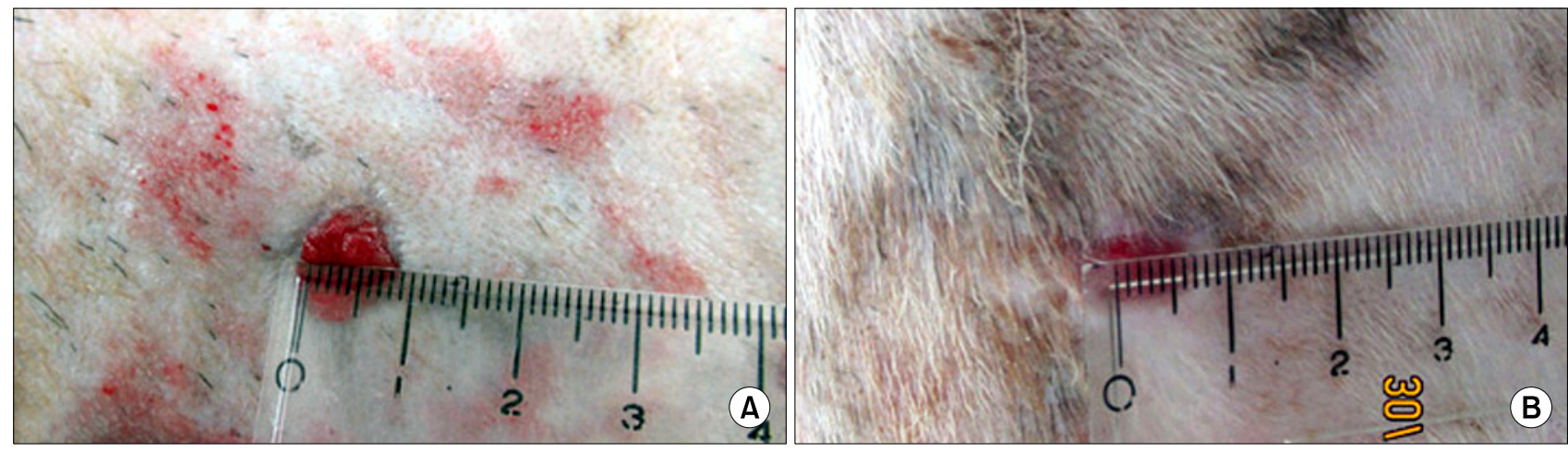

Fig. 1. Photographs showing the wound area in the two groups at $14^{\text {th }}$ day of treatment: (A) wound area from Group-l treated with saline compared to (B) wound area from Group-ll treated with exosomes. 
Table 1. Percentage of wound reduction size (compared to initial wound size) and the contraction difference between saline and exosomes groups

\begin{tabular}{lccc}
\hline & Saline & Exosomes & Exosomes vs Saline \\
\hline Day 3 & $0 \%$ & $7.5 \%$ & $7.5 \%$ \\
Day 7 & $20 \%$ & $40 \%$ & $20 \%$ \\
Day 14 & $65 \%$ & $72.5 \%$ & $7.5 \%$ \\
\hline
\end{tabular}

\section{Histological evaluation of wound healing}

Histopathological examination: Histopathological evaluation of induced wounds of the control group at the $3^{\text {rd }}$ day post-wounding disclosed evident wound edges and complete removal of epidermis in the surface of the wound area. The dermis was populated with inflammatory exudates mainly neutrophils, fibrin deposition admixed with necrotic tissue debris, in addition to newly formed capillaries (angiogenesis) that populated the area with proliferation of fibroblasts (Fig. 3A).

At the $7^{\text {th }}$ day, the wound edges were reduced with proliferation of kerationcytes. The re-epithelialized wound was higher than the surrounding surface. Most of the cells from the previous stage of repair appeared to have migrated from the wound site, with the exception of few inflammatory exudates and clotted blood that were still present. The extracellular matrix in the dermis revealed formation of disorganized collagen under the re-epithelialized surface. Outside the wound area, the epidermis, the skin appendages and the collagen were intact (Fig. 3C).

At the $14^{\text {th }}$ day post-wounding, the wound surface showed complete re-epithelialization with large amount of granulation tissue that has been formed under the re-epithelialized epidermis with few disorganized immature collagen (extracellular matrix) laid down. Outside the wound area, intact epidermis, mature collagen fibers and skin appendages were observed (Fig. 3E). Disorganized few collagen produced by proliferative fibroblast that have migrated into the wound were observed and stained positively with Masson's trichrome (Fig. 3G).

Histopathological evaluation of induced wounds injected with MSC-derived exosomes at the $3^{\text {rd }}$ day after wounds induction, disclosed apparent wound edges that were populated with inflammatory exudates mainly neutrophils and macrophages with fibrin deposition and necrotic tissue debris. Also newly formed blood capillaries (angiogenesis) were populate at the area with proliferation of large number of fibroblasts and few disorganized collagen (the extracellular matrix). Outside the wound area, the epidermis and the skin appendages were intact with

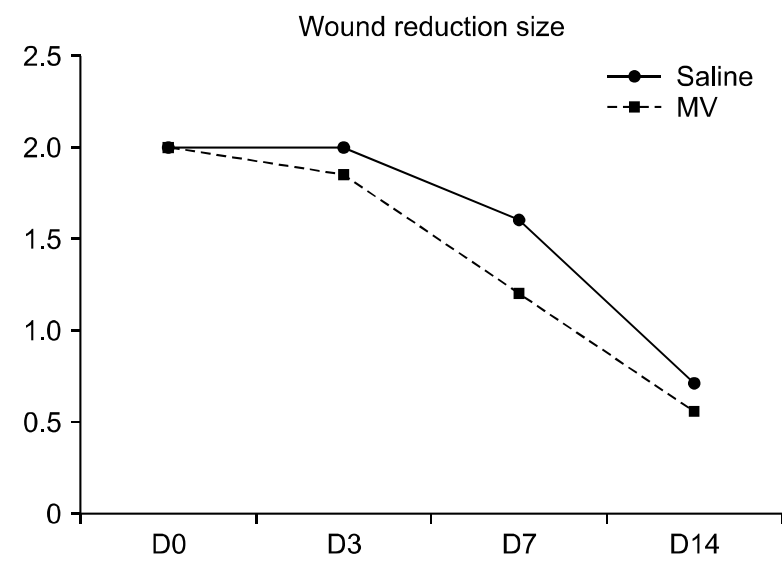

Fig. 2. Graph showing increased wound-size reduction $\%$ in wounds treated with saline and exosomes at 3, 7 and 14 days.

mature organized collagen in the dermis (extracellular matrix) (Fig. 3B).

While at the $7^{\text {th }}$ day the wound area had contracted with narrowing of its edges, collagen has been laid down under the re-epithelialized wound surface and was associated with the newly formed blood capillaries and few fibroblasts with intact skin appendages (Fig. 3D).

At the $14^{\text {th }}$ day, wound sites showed enhanced cellularity, complete re-epithelization and closure of wound. Tissue remodeling took place below the epidermal surface and mature collagen (extracellular matrix) was laid down in the dermis. The skin appendages and the blood vessels were intact (Fig. 3F). Enhanced dermal fibroblasts and large amount of mature organized collagen deposition were stained positive with Masson's trichrome stain (Fig. 3H).

Immunohistochemistry: Immunohistochemical staining of skin wound sections of control group at 3 days revealed mild expression of both angiogenesis markers CD31 and $\alpha$-SMA. While at $7^{\text {th }}$ and $14^{\text {th }}$ days, moderate positive expression of both markers was noticed with the existence of large number of macrophages and lymphocytes (Figs. 4, 5).

Wound sections treated with MSC-derived exosomes, revealed variable degrees of CD31 and $\alpha$-SMA markers expression. At the $3^{\text {rd }}$ day of treatment, mild expression of the two markers was observed. High expression of the markers was evident at the $7^{\text {th }}$ day of treatment followed by moderate expression of both markers at the 14th day of treatment (Figs. 4, 5).

\section{Discussion}

It was originally thought that MSCs homed to injured tissue differentiate into various cell types such as chon- 

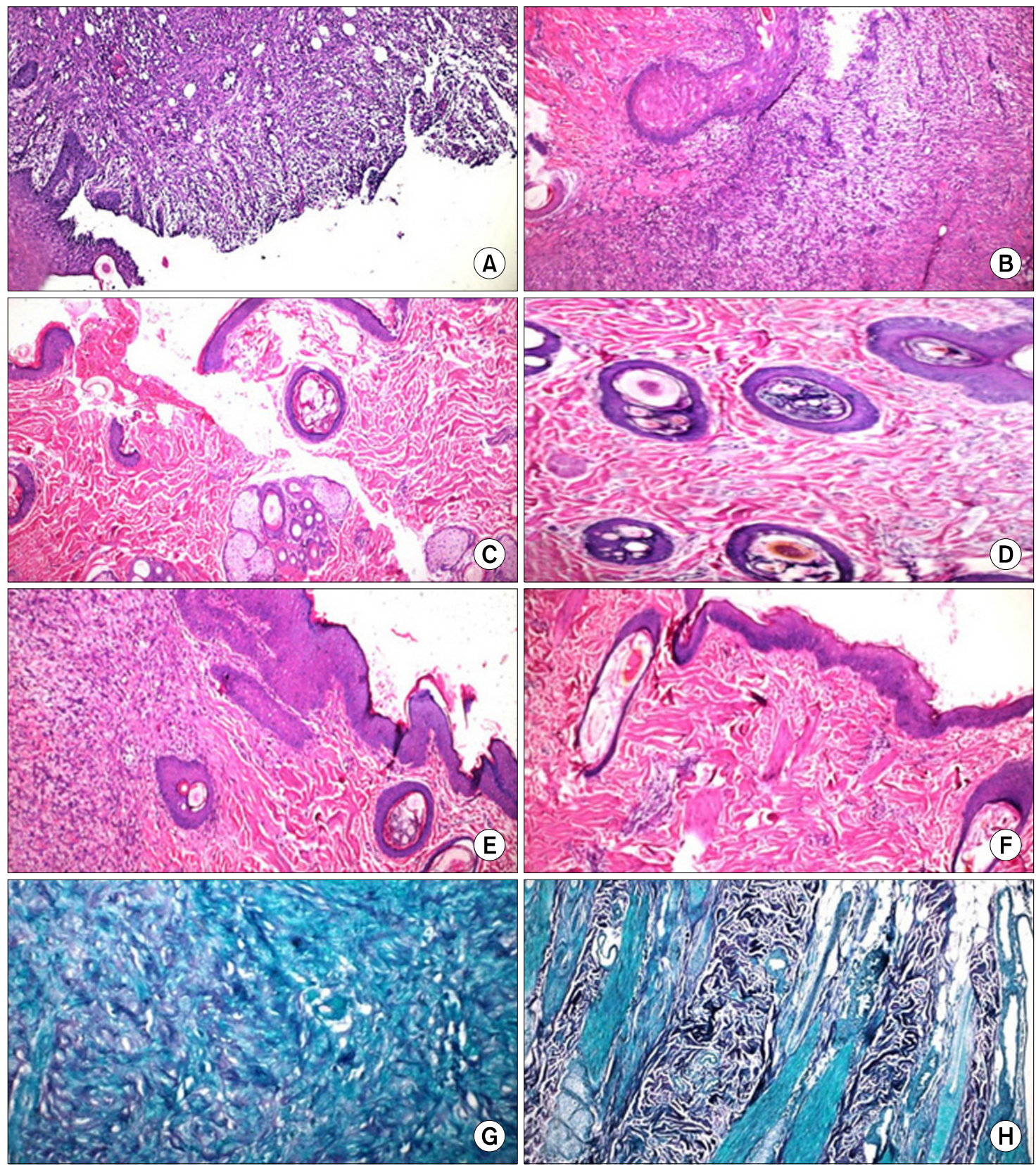

Fig. 3. Histopathological skin sections of wounds treated with saline and exosomes: (A) Group-l at 3 days of treatment disclosing the wound edge, complete removal of epidermis in wound area. The dermis has inflammatory exudates, fibrin deposition admixed with necrotic tissue debris and new blood capillaries. H\&E $\times 100$; (B) Group-II at 3 days revealing wound edges populated with inflammatory exudates, fibrin deposition, necrotic debris and newly formed blood capillaries with proliferation of fibroblasts and few disorganized collagen. H\&E $\times 400$; (C) Group-I at the $7^{\text {th }}$ day showing reduced wound edges and proliferation of kerationcytes. The re-epithelialized wound is higher than the surrounding surface. Most of the cells from the previous stage have migrated from the wound site, few inflammatory exudates and clotted blood are still present. The dermal extracellular matrix exhibits disorganized collagen under the re-epithelialized surface. H\&E $\times 100$; (D) Group-II at the $7^{\text {th }}$ day: wound area has contracted. Collagen has been laid down under the re-epithelized wound surface associated with newly formed blood capillaries and few fibroblasts with intact skin appendages. H\&E $\times 400$; (E) Group-I at the $14^{\text {th }}$ day of treatment showing complete re-epithelialization of wound surface, large amount of granulation tissue formation under the re-epithelialized epidermis with few disorganized immature collagen. $\mathrm{H} \& \mathrm{E} \times 100$; $(\mathrm{F})$ Group-II at the $14^{\text {th }}$ day showing complete re-epithelialization of wound surface with complete wound closure, tissue remodeling took place below the epidermal surface and mature collagen laid down in the dermis, the skin appendages and the blood vessels are intact. H\&E×200; (G) Masson's trichrome stain section, Group-l, day 14, showing few disorganized collagen and fibroblastic proliferation $\times 400$; (H) Masson's trichrome section, Group-Il, day 14, showing large amount of collagen deposition $\times 200$. 

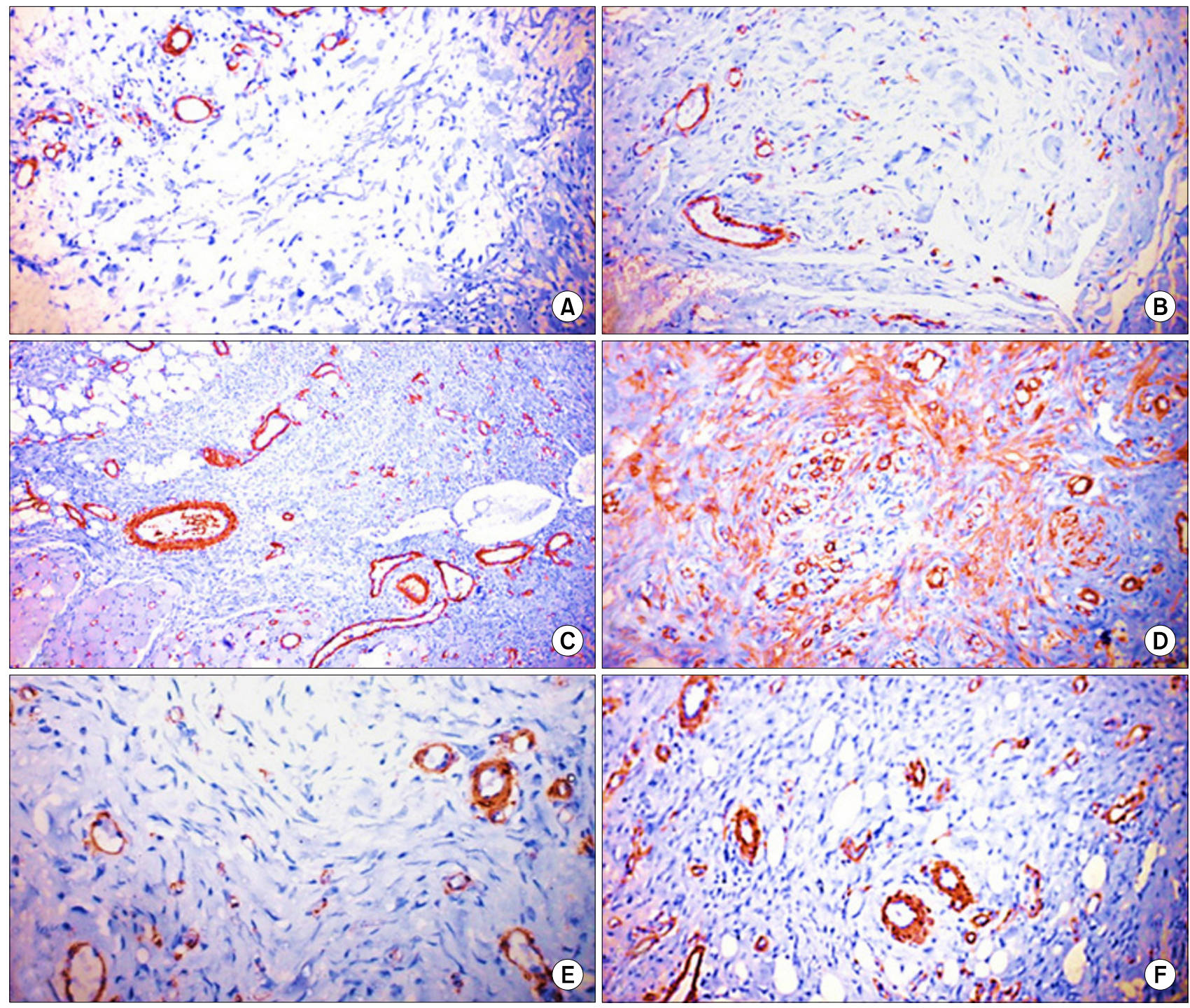

Fig. 4. $\alpha$-SMA-Immunohistochemistry of skin wound sections: (A) Group-I, 3 days of treatment disclosing mild expression of $\alpha$-SMA. Immunoperoxidase $\times 200$; (B) Group-II, 3 days of treatment showing mild immunoreactivity. Immunoperoxidase $\times 400$; (C) Group-I, 7 days of treatment revealing moderate positive expression of $\alpha$-SMA. Immunoperoxidase $\times 200$; (D) Group-II, 7 days of treatment disclosing, marked positive expression of $\alpha$-SMA. Immunoperoxidase $\times 200$; (E) Group-I at 14 days of treatment showing moderate immunoreactivity. Immunoperoxidase $\times 400$; (F) Group-II, 14 days of treatment revealing moderate positive expression of $\alpha$-SMA. Immunoperoxidase $\times 200$.

drocytes, adipocytes, osteoblasts or endothelial cells and replace damaged tissue $(7,8)$. However, subsequent studies have shown that MSC engraftment and differentiation to injured sites are low and transient (4).

Conversely, it has now emerged that MSCs may predominantly act in a paracrine fashion and secretory factors being the mediators of tissue repair and wound healing (9-11). Exosomes are one of the many secretory factors released by the MSCs $(7,8)$ and have been described as the most important effective ingredients that play an important role in cell-to-cell communication $(12,13)$. Thus, it was hypothesized that if the benefits of stem cell ther- apy are mediated by its exosomal secretions, then direct treatment with these exosomes may overcome the limitations and risks associated with stem cell therapy $(6,7)$.

Faster epithelialization, following BM-derived stem cell transplantation for cutaneous wound healing, has been published in previous studies on rabbits, mice, rats and pigs (14-17) but not on dogs.

In the present study three bilateral full thickness circular wounds were created on the back of six dogs using 2 $\mathrm{cm}$ dermal punch similar to $(6,18,19)$. The wounds were $2 \mathrm{~cm}$ in diameter as estimated to be the Critical Size Defect $(\mathrm{CSD})$ for $\operatorname{dogs}(20,21)$. And they were at least 

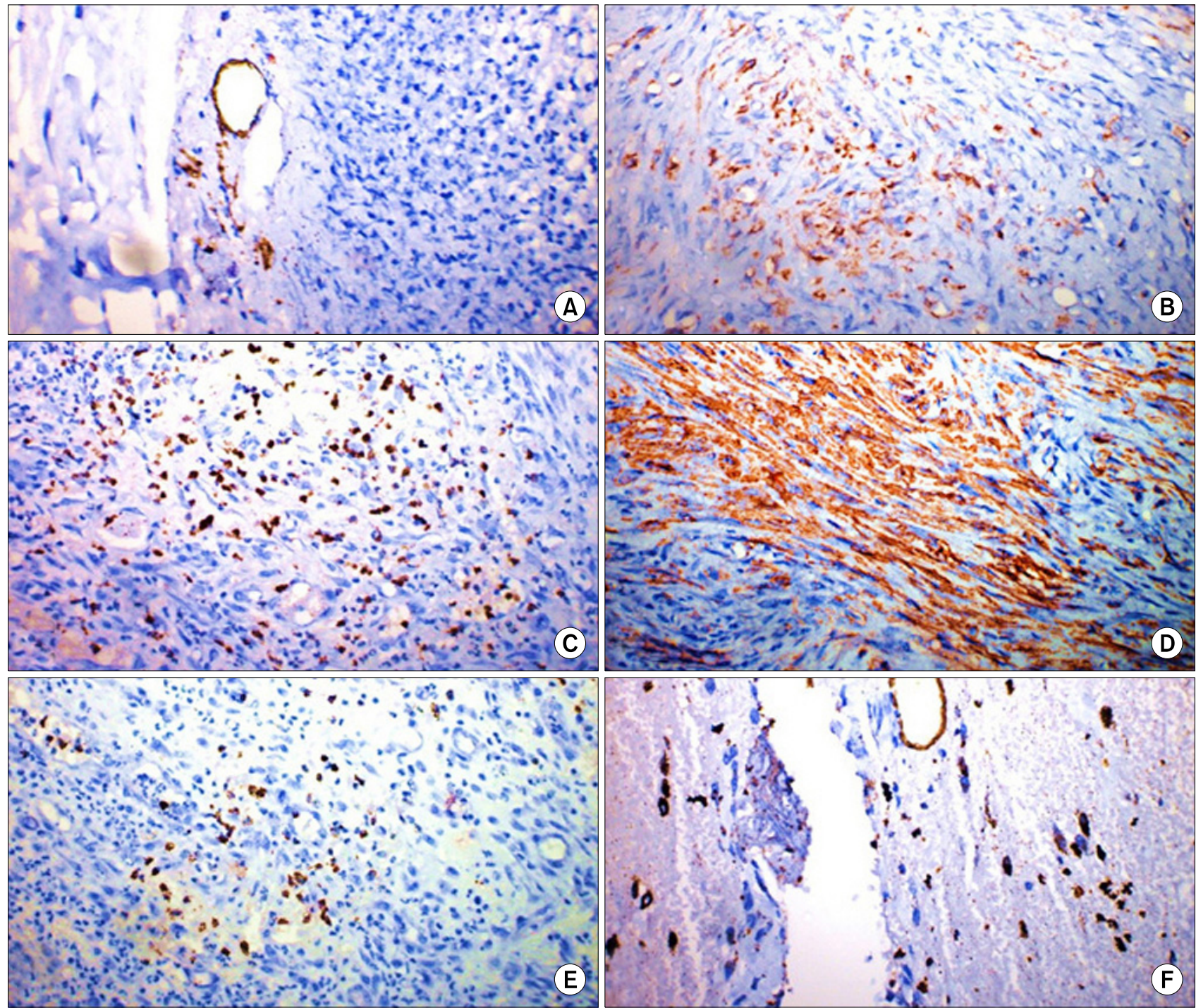

Fig. 5. CD31-Immunohistochemistry of skin wound sections: (A) Group-I, 3 days of treatment revealing scarce immunoreactivity. Immunoperoxidase $\times 400$; (B) Group-II, 3 days of treatment revealing limited immunoreactivity. Immunoperoxidase $\times 200$; (C) Group-I, 7 days of treatment revealing moderate positive expression of CD31 with large number of macrophages and lymphocytes. Immunoperoxidase $\times 100$; (D) Group-II, 7 days of treatment disclosing marked positive expression of CD31. Immunoperoxidase $\times 400$; (E) Group-I, 14 days of treatment disclosing few capillaries formation with infiltration of lymphocytes and macrophages. Immunoperoxidase $\times 400$; $(\mathrm{F})$ Group-II, 14 days of treatment showing moderate immunoreactivity and moderate angiogenesis. Immunoperoxidase $\times 400$.

\section{$2.5 \mathrm{~cm}$ apart (18).}

One month before the commence of the experimental wounds, fresh BM was aspirated from the iliac crest of healthy dogs under general anesthesia then MSCs were isolated and cultured similar to $(18,22,23)$. Other possibilities for obtaining BM included the femur (24) and the humerus (25).

Studies have reported a strong direct-correlation between the number of cells applied per $\mathrm{cm}^{2}$ of the wound surface and the subsequent decrease in wound size. It was suggested that at least $1 \times 10^{6}$ cells $/ \mathrm{cm}^{2}$ of wound is needed for a significant therapeutic effect (17). In this study, the amount of exosomes used is the amount of exosomes obtained from $2 \times 10^{6} \mathrm{MSC} /$ wound similar to $(19,26,27)$. The route of administration of the therapeutic material also varied. Cell-treatment could be achieved through intra-dermal injection $(18,26)$, local and systemic injection $(27,28)$, or spray $(17)$. Topical methods were statistically more effective than other routes of administration. In this study the exosomal solution was subcutaneously injected in 4 places around each wound similar to $(6,29)$.

The present work demonstrated better and faster heal- 
ing of the exosomes treated wound compared with the control group. Dogs treated with MSC-Exosomes showed faster wound closure than observed in the control group at Days 3, 7, and 14 post-wounding. Reduced scar widths and increased collagen maturity were parameters used to assess the degree of wound healing. The gross evaluation of exosomes-treated wounds revealed early and better wound contraction and closure of wounds, early crustation and deposition of healthy granulation tissue consequently resulting in complete healing and covering of wound with regenerated skin by the end of the second week. On the other hand, delayed crustation, deposition of unhealthy granulation tissue and delayed closure of the wound in the control group. The MSC-Exosomal treatment significantly enhanced wound reduction compared to that observed in the control group. The narrowest scar widths and largest collagen deposition areas were observed in the MSC-Exosomes group at days 14 post-wounding, compared to the control group. The macroscopic findings revealed that, the wound size reduction percentage for the exosomes treated group was $7.5 \%$ at the $3^{\text {rd }}$ day, $40 \%$ at the $7^{\text {th }}$ day and $72.5 \%$ the $14^{\text {th }}$ day after treatment. While, the wound size reduction percentage for the control group was $0 \%$ at the $3^{\text {rd }}$ day, $20 \%$ at the $7^{\text {th }}$ day and $65 \%$ at the $14^{\text {th }}$ after treatment. The peak of wound reduction was during the second week post-treatment in both groups.

Exosomes are proven to contribute to an important mechanism for cutaneous wound healing including proangiogenic effects (increase angiogenesis and enhance tubular formation), activating wound-healing pathways as well as promoting growth factor secretion and collagen synthesis $(6,30)$.

The histological samples were taken at the $3^{\text {rd }}, 7^{\text {th }}$ and the $14^{\text {th }}$ day post-treatment similar to (6). In previous studies, histological sampling varied from twelve days (31), five weeks (18) and six weeks (32).

Evidences of rapid re-epithelialization, increased collagen deposition and angiogenesis following topical injection of exosomes were noticed. By the end of the second week, complete re-epithelialization of wound surface and collagen deposition and intact hair follicles were evident at day $14^{\text {th }}$ post-wounding at the exosomes group while, the re-epithelized wound was slightly higher than the surrounding surface at the saline group (33).

Dermal fibroblasts provide critical functions during wound healing, including wound contraction, extracellular matrix deposition, and tissue remodeling (30), providing a scaffold for the assembly of neighboring cells at wound margins and consequently contributing to wound closure. On the instance of skin wound, fibroblasts present in the dermis proliferate rapidly and migrate to wound site where they can secrete type I and III collagens and elastin, which are the central components of the extracellular matrix $(34,35)$. Studies have demonstrated that a paracrine mechanism of MSCs (conducted through exosomes) is involved in promoting the proliferation, migration, and collagen secretion of fibroblasts (36).

The finding showed new capillaries formation with fibroblasts and few collagen deposition at $7^{\text {th }}$ day post-wounding at exosomes group, while, inflammatory cells, few new capillaries and few fibroblast cells were present at the $7^{\text {th }}$ day post-wounding at the control group.

Masson's trichrome staining was used to determine the degree of collagen synthesis $(6,18)$. Evidences suggested that MSC-Exosomes have stimulated the proliferation and migration of dermal fibroblasts and large amount of collagen deposition in the wound at $14^{\text {th }}$ day after treatment with MSC-Exosomes. On the other hand, Masson's trichrome stain showing disorganized few collagen and proliferation of fibroblasts in the wound at $14^{\text {th }}$ day post wounding in control group.

Vascularization is an essential step in the wound-healing process, angiogenesis and maturation of the new blood vessels is necessary to maintain a healthy granulation tissue $(14,34)$. To study exosome-induced angiogenesis during the wound healing process, CD31 and alpha smooth muscle actin ( $\alpha$-SMA) were detected. The newly formed vessels were detected by CD31 positive staining, whereas, mature vessels were characterized as CD31 and $\alpha$-SMA double-positive vascular structures $(6,18,37,38)$.

Results showed that the number of newly formed vessels and mature vessels both have increased alongside the healing process. The MSC derived exosomes group showed the highest vessel densities and numbers of mature vessels, compared with the control group. The exosomes-treated group had more CD31 positive cells in the wound area than control group at both $1^{\text {st }}$ and $2^{\text {nd }}$ weeks after treatment. Results also revealed that the granulation tissue angiogenesis was more active in wounds treated with MSC-derived exosomes than those in the control group at both $1^{\text {st }}$ and $2^{\text {nd }}$ weeks. These findings indicated that exosomes have improved the angiogenesis, in agreement with similar results (6).

The highest increase expression of the two markers was at $7^{\text {th }}$ day of treatment indicating significant angiogenesis and high rate of cellular regenerative activities. Moderate positive expression of CD31 and $\alpha$-SMA were noticed at $14^{\text {th }}$ day of treatment indicating moderate angiogenesis, which agree with (18).

Exosomes treated group exhibited reduced permeability 
of the capillary membrane, less fibrosis, decreased inflammation than the control group, all of which had contributed to a better tissue repair. The superior and faster wound healing following the injection of exosomes can be explained by the release of cytokines which may have balanced the wound environment. Exosomes may also have induced better healing changes through the activation of growth factor that enhanced the proliferation and migration of wound fibroblasts and promoted angiogenesis (30).

These findings suggested that MSC-Exosomes have similar protective and reparative properties as their cellular counter parts in tissue repair. Moreover, MSC-Exosomes appeared to be a superior candidate for treating cutaneous wounds, and represented a promising opportunity to develop a novel cell-free therapy approach that might overcome the obstacles and risks associated with the use of native or engineered stem cells transplantation therapy $(3,39)$.

\section{Conclusion}

The findings demonstrated that MSCs derived exosomes significantly promote cutaneous wound healing, collagen synthesis, and vascularization at wound sites in a dog full-thickness skin defect model and showed more rapid wound closure. It was also concluded that the application of exosomes not only promoted the generation of newly formed vessels, but also have accelerated their maturation at wound sites.

\section{Potential conflict of interest}

The authors have no conflicting financial interest.

\section{References}

1. Gurtner GC, Werner S, Barrandon Y, Longaker MT. Wound repair and regeneration. Nature 2008;453:314-321

2. Maxson S, Lopez EA, Yoo D, Danilkovitch-Miagkova A, Leroux MA. Concise review: role of mesenchymal stem cells in wound repair. Stem Cells Transl Med 2012;1:142149

3. Camussi G, Deregibus MC, Cantaluppi V. Role of stem-cell-derived microvesicles in the paracrine action of stem cells. Biochem Soc Trans 2013;41:283-287

4. Yu B, Zhang X, Li X. Exosomes derived from mesenchymal stem cells. Int J Mol Sci 2014;15:4142-4157

5. Fleissner F, Goerzig Y, Haverich A, Thum T. Microvesicles as novel biomarkers and therapeutic targets in transplantation medicine. Am J Transplant 2012;12:289-297

6. Zhang J, Guan J, Niu X, Hu G, Guo S, Li Q, Xie Z, Zhang $\mathrm{C}$, Wang Y. Exosomes released from human induced pluripotent stem cells-derived MSCs facilitate cutaneous wound healing by promoting collagen synthesis and angiogenesis. J Transl Med 2015;13:49

7. Rani S, Ryan AE, Griffin MD, Ritter T. Mesenchymal stem cell-derived extracellular vesicles: toward cell-free therapeutic applications. Mol Ther 2015;23:812-823

8. Tögel F, Weiss K, Yang Y, Hu Z, Zhang P, Westenfelder C. Vasculotropic, paracrine actions of infused mesenchymal stem cells are important to the recovery from acute kidney injury. Am J Physiol Renal Physiol 2007;292:F1626-F1635

9. Shabbir A, Zisa D, Suzuki G, Lee T. Heart failure therapy mediated by the trophic activities of bone marrow mesenchymal stem cells: a noninvasive therapeutic regimen. Am J Physiol Heart Circ Physiol 2009;296:H1888-H1897

10. Shabbir A, Zisa D, Leiker M, Johnston C, Lin H, Lee T. Muscular dystrophy therapy by nonautologous mesenchymal stem cells: muscle regeneration without immunosuppression and inflammation. Transplantation 2009;87: 1275-1282

11. Gnecchi M, Zhang Z, Ni A, Dzau VJ. Paracrine mechanisms in adult stem cell signaling and therapy. Circ Res 2008;103:1204-1219

12. Simons M, Raposo G. Exosomes--vesicular carriers for intercellular communication. Curr Opin Cell Biol 2009;21: 575-581

13. Kinnaird T, Stabile E, Burnett MS, Lee CW, Barr S, Fuchs S, Epstein SE. Marrow-derived stromal cells express genes encoding a broad spectrum of arteriogenic cytokines and promote in vitro and in vivo arteriogenesis through paracrine mechanisms. Circ Res 2004;94:678-685

14. Borena BM, Pawde AM, Amarpal, Aithal HP, Kinjavdekar P, Singh R, Kumar D. Evaluation of autologous bone marrow-derived nucleated cells for healing of full-thickness skin wounds in rabbits. Int Wound J 2010;7:249-260

15. Luo G, Cheng W, He W, Wang X, Tan J, Fitzgerald M, Li X, Wu J. Promotion of cutaneous wound healing by local application of mesenchymal stem cells derived from human umbilical cord blood. Wound Repair Regen 2010; 18:506-513

16. Badiavas EV, Ford D, Liu P, Kouttab N, Morgan J, Richards A, Maizel A. Long-term bone marrow culture and its clinical potential in chronic wound healing. Wound Repair Regen 2007;15:856-865

17. Falanga V, Iwamoto S, Chartier M, Yufit T, Butmarc J, Kouttab N, Shrayer D, Carson P. Autologous bone marrow-derived cultured mesenchymal stem cells delivered in a fibrin spray accelerate healing in murine and human cutaneous wounds. Tissue Eng 2007;13:1299-1312

18. Kim JW, Lee JH, Lyoo YS, Jung DI, Park HM. The effects of topical mesenchymal stem cell transplantation in canine experimental cutaneous wounds. Vet Dermatol 2013;24: 242-e53

19. Fu X, Fang L, Li X, Cheng B, Sheng Z. Enhanced wound-healing quality with bone marrow mesenchymal stem cells autografting after skin injury. Wound Repair Regen 2006;14:325-335

20. Karayannopoulou M, Tsioli V, Loukopoulos P, Anagnostou 
TL, Giannakas N, Savvas I, Papazoglou LG, Kaldrymidou E. Evaluation of the effectiveness of an ointment based on Alkannins/Shikonins on second intention wound healing in the dog. Can J Vet Res 2011;75:42-48

21. Adam JA. A simplified model of wound healing (with particular reference to the critical size defect). Mathematical and Computer Modelling 1999;30:23-32

22. Ansari MM, Sreekumar TR, Chandra V, Dubey PK, Kumar GS, Amarpal, Sharma GT. Therapeutic potential of canine bone marrow derived mesenchymal stem cells and its conditioned media in diabetic rat wound healing. J Stem Cell Res Ther 2013;3:141

23. Hiyama A, Mochida J, Iwashina T, Omi H, Watanabe T, Serigano K, Tamura F, Sakai D. Transplantation of mesenchymal stem cells in a canine disc degeneration model. J Orthop Res 2008;26:589-600

24. Zhang Y, Lin HK, Frimberger D, Epstein RB, Kropp BP. Growth of bone marrow stromal cells on small intestinal submucosa: an alternative cell source for tissue engineered bladder. BJU Int 2005;96:1120-1125

25. Bhattacharya V, McSweeney PA, Shi Q, Bruno B, Ishida A, Nash R, Storb RF, Sauvage LR, Hammond WP, Wu $\mathrm{MH}$. Enhanced endothelialization and microvessel formation in polyester grafts seeded with $\mathrm{CD} 34(+)$ bone marrow cells. Blood 2000;95:581-585

26. Abd-Allah SH, El-Shal AS, Shalaby SM, Abd-Elbary E, Mazen NF, Abdel Kader RR. The role of placenta-derived mesenchymal stem cells in healing of induced full-thickness skin wound in a mouse model. IUBMB Life 2015; 67:701-709

27. Basiouny HS, Salama NM, Maadawi ZM, Farag EA. Effect of bone marrow derived mesenchymal stem cells on healing of induced full-thickness skin wounds in albino rat. Int J Stem Cells 2013;6:12-25

28. Tark KC, Hong JW, Kim YS, Hahn SB, Lee WJ, Lew DH. Effects of human cord blood mesenchymal stem cells on cutaneous wound healing in leprdb mice. Ann Plast Surg 2010;65:565-572

29. Chen L, Tredget EE, Wu PY, Wu Y. Paracrine factors of mesenchymal stem cells recruit macrophages and endothelial lineage cells and enhance wound healing. PLoS One 2008;3:e1886

30. Shabbir A, Cox A, Rodriguez-Menocal L, Salgado M, Van Badiavas E. Mesenchymal stem cell exosomes induce proliferation and migration of normal and chronic wound fibroblasts, and enhance angiogenesis in vitro. Stem Cells Dev 2015;24:1635-1647

31. Azari O, Babaei H, Derakhshanfar A, Nematollahi-Mahani SN, Poursahebi R, Moshrefi M. Effects of transplanted mesenchymal stem cells isolated from Wharton's jelly of caprine umbilical cord on cutaneous wound healing; histopathological evaluation. Vet Res Commun 2011;35:211-222

32. Nakagawa H, Akita S, Fukui M, Fujii T, Akino K. Human mesenchymal stem cells successfully improve skin-substitute wound healing. Br J Dermatol 2005;153:29-36

33. Shi W, Liu L, Li J, Qu L, Pang X, Yu H, Zhang Y, Wang T. Bioactive flavonoids from Flos Sophorae. J Nat Med 2017;71:513-522

34. Singer AJ, Clark RA. Cutaneous wound healing. N Engl J Med 1999;341:738-746

35. Martin P. Wound healing--aiming for perfect skin regeneration. Science 1997;276:75-81

36. Chen L, Xu Y, Zhao J, Zhang Z, Yang R, Xie J, Liu X, Qi S. Conditioned medium from hypoxic bone marrow-derived mesenchymal stem cells enhances wound healing in mice. PLoS One 2014;9:e96161

37. Hattori N, Mochizuki S, Kishi K, Nakajima T, Takaishi H, D'Armiento J, Okada Y. MMP-13 plays a role in keratinocyte migration, angiogenesis, and contraction in mouse skin wound healing. Am J Pathol 2009;175:533-546

38. Benjamin LE, Golijanin D, Itin A, Pode D, Keshet E. Selective ablation of immature blood vessels in established human tumors follows vascular endothelial growth factor withdrawal. J Clin Invest 1999;103:159-165

39. Baglio SR, Pegtel DM, Baldini N. Mesenchymal stem cell secreted vesicles provide novel opportunities in (stem) cell-free therapy. Front Physiol 2012;3:359 